\title{
Sinonasal Ultrastructure of the Hematopoietic Stem Cell Transplant and Chronic Graft-versus-host Disease with Rhinosinusitis
}

\author{
Érica Ortiz ${ }^{1 *}$, Luciana R Meirelles ${ }^{2}$, Afonso C Vigorito ${ }^{3}$, Eulália Sakano ${ }^{1}$ and Ester Maria Danielli Nicola ${ }^{1}$ \\ ${ }^{1}$ Otolaryngology Department of UNICAMP, Campinas, Sao Paulo, Brazil \\ ${ }^{2}$ Pathology Department of UNICAMP, Campinas, Sao Paulo, Brazil
}

${ }^{3}$ Haemathology Department of UNICAMP, Campinas, Sao Paulo, Brazil

\begin{abstract}
Introduction: It is believed that immunosuppression is the sole cause for the occurrence of rhinosinusitis in hematopoietic stem cell transplant (HSCT). There is a high incidence of sinusitis in recipient patients, especially in those with Chronic Graft Versus Host disease (GVHD). Histopathological abnormalities were described in recipients' sinus mucosa compared to immunocompetent patients. There were also mucosal abnormalities related to cytotoxicity in the transplanted patients with chronic GVHD but no difference in ultrastructure between HSCT patients with and without GVHD, except for increased goblet cells in patients without GVHD. The relation between the sinonasal mucosa abnormalities of these patients and rhinosinusitis is not well established yet.
\end{abstract}

Objective: To verify the ultrastructure of the sinonasal mucosa of HSCT with and without GVHD with rhinosinusitis to understand the cause of high Sinusitis incidence.

Method: prospective study with statistical analysis of data obtained from the evaluation of the uncinate process mucosa of patients transplanted with (16) and without GVHD (8) with rhinosinusitis by transmission electron and optical microscopy.

Results: Of the patients, $47 \%$ (14) had only 1 or 2 episodes, and $33 \%$ had more than 3 episodes of rhinosinusitis. Only the presence of microvilli was significantly higher in patients without GVHD. There was no significant difference in the amount of cilia, ciliary ultrastructure, squamous metaplasia, goblet cells, vacuolization, density of the inflammatory infiltrate, intraepithelial lymphocytes, eosinophils, mucous glands, apoptotic corpuscles intraepithelial basement membrane thickness, edema and subepithelial fibrosis between groups. There was a significant decrease of cilia with Powered by Editorial Manager ${ }^{\mathbb{B}}$ and ProduXion Manager ${ }^{\circledR}$ from Aries Systems Corporation higher recurrence of rhinosinusitis.

Conclusion: There was an increase in microvilli HSCT without GVHD with rhinosinusitis, and the ultrastructure and histological changes of HSCT with and without GVHD did not change with the recurrence of rhinosinusitis. However, there was a decrease of cilia in the epithelium of the sinonasal HSCT with higher recurrence of rhinosinusitis

Keywords: Sinusitis; Hematopoietic stem cell transplant; Graftversus-host-disease; Uncinate process

\section{Introduction}

The respiratory epithelium has sinonasal mechanical and immunological barriers for its protection against microbes or irritants coming from the external environment. These barriers are the ciliated pseudostratified epithelium (ciliated cells and tight junctions), mucociliary clearance and innate immunity (mucosa or nasal-associated lymphoid tissue; MALT or NALT). The highest incidence (37\%), recurrence and chronicity of rhinosinusitis in patients submitted to hematopoietic stem cell transplants are due mainly to immunosuppression, which modifies the innate immunity. The frequency of bacterial rhinosinusitis can reach $49 \%$ in these patients, compared to only $5-15 \%$ in immunocompetent individuals [1].

Immunosuppressive drugs, total body irradiation, high doses of chemotherapy and chronic graft versus host disease (GVHD) are predictive or aggravating factors described for the development of rhinosinusitis in patients undergoing hematopoietic stem cell transplantation (HSCT) [2-5]. There is a 4.3 times greater risk for the occurrence of rhinosinusitis in patients who developed chronic GVHD [6]. This disease is a cytotoxicity reaction that affects the respiratory, gastrointestinal and vaginal mucosal systems, as well as the skin, the eyes and the liver [7-10].

In our previous study, we demonstrated that $77 \%$ of HSCT patients had decreased or absent cilia, and 50\% had ultrastructural abnormalities of the cilia after these transplants, even without the occurrence of rhinosinusitis [11]. By contrast, ciliary beating was altered or absent in only 23 to $28 \%$ of chronic and recurrent rhinosinusitis for immunocompetent patients due to the decrease or absence of cilia or ciliated cells, as well as to the disorientation of the cilia $[1,6-8]$. It has been suggested that these abnormalities might lead to an increased RS incidence due to mucociliary clearance changes, as well as to immunosuppression [11,12]. However, the correlation between histopathological abnormalities and rhinosinusitis has not yet been established, i.e., whether it is the sinusitis that causes the histopathological abnormalities or the abnormalities that precipitate a higher incidence of sinusitis in these patients [12].

*Corresponding author: Erica Ortiz, MD, Faculdade de Ciencias Médicas, Caixa Postal 6111 - Cidade Universitária "Zeferino Vaz", Campinas, São Paulo, Brazil Tel: 55-19-3521-7523; Fax: 55-19-3521-7454; E-mail: erica.ortiz@terra.com.br

Received December 08, 2013; Accepted January 04, 2014; Published January 06, 2014

Citation: Ortiz É, Meirelles LR, Vigorito AC, Sakano E, Nicola EMD (2014) Sinonasal Ultrastructure of the Hematopoietic Stem Cell Transplant and Chronic Graft-versus-host Disease with Rhinosinusitis. J Stem Cell Res Ther 4: 157. doi:10.4172/2157-7633.1000157

Copyright: (C) 2014 Ortiz É, et al. This is an open-access article distributed unde the terms of the Creative Commons Attribution License, which permits unrestricted use, distribution, and reproduction in any medium, provided the original author and source are credited. 
In immunocompetent patients, there is evidence of anatomical, ciliary and mucus viscosity alterations that may trigger exacerbate or maintain the occurrence of rhinosinusitis. By contrast, it is believed that rhinosinusitis can cause pathological damage in the sinus mucosa, perpetuating or exacerbating the local inflammation $[13,14]$.

\section{Objective}

The aims of this study were to verify the histology and ultrastructure of the sinonasal mucosa of those patients who underwent hematopoietic stem cell transplants with rhinosinusitis between the groups with and without GVHD. Second, this study aimed to verify whether the HSCT and/or the rhinosinusitis influenced the development of sinonasal histological abnormalities.

\section{Method}

This is a prospective exploratory cross-sectional study of patients undergoing hematopoietic stem cell transplants at the Department of Bone Marrow Transplantation (BMT - Department of Hematology) at the Otorhinolaryngology Department of the University of Campinas, São Paulo, Brazil. This study was approved by the Ethics Committee in Research of FCM UNICAMP under number 088-2002.

We selected 30 patients who underwent an allogeneic hematopoietic stem cell transplant, of whom nine (9) had no GVHD and 21 had chronic GVHD. The transplant recipients were selected independently of the type of donor and GVHD prophylaxis. All of them had rhinosinusitis at the time of the study, except for six (6) of these patients, who were separated from the analysis. Then, they were divided into two groups: one group of 16 patients with GVHD and rhinosinusitis and another group of 8 without GVHD and with rhinosinusitis.

The exclusion criteria were patients with a serious risk of bleeding due to thrombocytopenia and patients with cytomegalovirus (CMV) or herpes virus.

Thirty patients with an average age of 39 years and a male predominance $(63 \%)$ were transplanted with allogeneic hematopoietic stem cells. A total of $73 \%$ underwent myeloablative transplantation, and $27 \%$ underwent non-myeloablative. Of the 24 patients who had rhinosinusitis, $47 \%$ (14) had only 1 or 2 episodes, and $33 \%$ had more than 3 episodes of rhinosinusitis. Table 1 lists the general characteristics of the groups of transplanted patients with and without GVHD and rhinosinusitis.

Biopsies of the uncinate process mucosa at the middle meatus were performed for all patients under anesthesia by endoscopy [15]. Histopathological evaluation was performed by optical microscopy and transmission electron microscopy (TEM). We used hematoxylin-eosin staining (HE), Periodic acid - Schiff (PAS) and Masson's trichrome (Massom) for a better assessment of each variable. The histologic criteria analyzed by light microscopy in HE were the density and composition of epithelial and submucosal inflammatory infiltrate; the apoptotic bodies and intraepithelial eosinophils; and the submucosal glandular density. The intraepithelial lymphocyte counts and the density of epithelial and submucosal inflammatory infiltrate analysis were done by PAS, and the basal membrane thickening, submucosal edema and fibrosis were determined by Masson's trichrome. The variable counts were determined by the analysis of the histological sections that were randomly selected from the best embedded glass slides using at least ten (10) fields per 40x high-power fields (HPF). The measurements of the basal membrane were made with the aid of a micrometer eyepiece graticule (Breslow strip) in histological sections stained with Masson's trichrome in ten (10) 40x high-power fields, which were also randomly selected areas where the material was well embedded. The values of the lymphocytes, eosinophils, apoptotic bodies and submucosal glands counts, as well as the basal membrane thickness, were summed and divided by the number of selected fields (arithmetic average) for a comparative analysis between the groups. The optical analysis per HPF of the inflammatory infiltrate density, edema and fibrosis were subjectively graded as absent, mild, moderate or severe.

For electron microscopy, the sample was placed in a permeable thin paper card on a hard wax and cut into fine fragments of approximately $0.3 \mathrm{~mm}$ diameter placed in a container with fixative $3 \%$ glutaraldehyde solution and maintained at $4^{\circ} \mathrm{C}$ for 3 hours. Then, the samples were processed through the wash steps and placed in a container with phosphate buffer. Various fragments of approximately $2 \mathrm{~mm}$ from the uncinate process were randomly selected and made into ultrathin sections 50-60 nm thick using an ultramicrotome diamond knife. The amplification used ranged from 1,600 to 20,000 times. The parameters subjectively evaluated by transmission electron microscopy were the following: amount of cilia (absent, decreased, normal), organization of cilia structure, squamous metaplasia (absent or present), microvilli (present or absent), goblet cells (absent, decreased, increased or normal), intracellular mitochondria (present or absent) and cytoplasm vacuolization (present or absent). The cilia orientation was measured by cross sections of at least 10 cilia, which were delineated as one perpendicular line between the central microtubules, arranged in the same direction and angle within a possible variation of $10^{\circ} \mathrm{C}$.

For light microscopy, all the slides were examined by two pathologists, and for electron microscopy, all the fragments of the biopsy were always evaluated by the same investigator.

The data collected from the biopsies were compared among the three groups using a statistical analysis of contingency (chi-squared), as well as the Wilcoxon and the R version 2.7.0. Copyright (C) 2008. The R Foundation for Statistical Computing. The level of significance ( $\mathrm{P}$ value) was set at 0.05 and a confidence interval of $95 \%$.

The data used as a control for comparison and discussion of this study were obtained from our previous study, the methodology of which was identical [11]. This study evaluated the histological aspects of the nasal mucosa of immunocompetent patients and also of patients undergoing bone marrow transplants without rhinosinusitis.

\section{Results}

The nasal mucosa analysis by optical microscopy among the groups

\begin{tabular}{|c|c|c|c|}
\hline & HSCT & Hematologic disease & Rhinosinusitis \\
\hline $\begin{array}{l}\text { With } \\
\text { GVHD }\end{array}$ & $\begin{array}{l}\text { Myeloablative: } 12(75 \%) \\
\text { Non-myeloablative: } 4(25 \%)\end{array}$ & $\begin{array}{l}\text { CLM: } 5(31 \%) \\
\text { ALM: } 5(31 \%) \\
\text { MM: } 2(12.5 \%) \\
\text { CLL: } 1(6 \%) \\
\text { AA: } 1(6 \%) \\
\text { MDS: } 2(12.5 \%)\end{array}$ & $\begin{array}{c}\text { 1-2 RS: } 9 \\
(56.2 \%) \\
3 \text { ou>RS: } 7 \\
(43.7 \%)\end{array}$ \\
\hline $\begin{array}{l}\text { Without } \\
\text { GVHD }\end{array}$ & $\begin{array}{l}\text { Myeloablative: } 5(62.5 \%) \\
\text { Non-myeloablative: } 3(37.5 \%)\end{array}$ & $\begin{array}{l}\text { ALL: } 2(25 \%) \\
\text { MM: } 1(12.5 \%) \\
\text { SCA: } 1(12.5 \%) \\
\text { AA: } 2(25 \%) \\
\text { MDS: } 2(25 \%)\end{array}$ & $\begin{array}{c}\text { 1-2 RS: } 6 \\
(75 \%) \\
3 \text { ou>RS: } 2 \\
(25 \%)\end{array}$ \\
\hline
\end{tabular}

Captions: HSCT: Hematopoietic Stem Cell Transplant; CML: Chronic Myeloid Leukemia; AML: Acute Myeloid Leukemia; MM: Multiple Myeloma; CLL: Chronic Lymphocytic Leukemia; AA: Aplastic Anemia; MDS: Myelodysplastic Syndrome; ALL: Acute Lymphoblastic Leukemia; SCA: Sickle Cell Anemia; RS: Rhinosinusitis Table 1: Groups of transplanted hematopoietic stem cells in patients with rhinosinusitis. 
of HSCT with and without GVHD and with rhinosinusitis showed no significant changes in any of the variables analyzed (Table 2). However, the inflammatory infiltrate density in patients with GVHD was moderate in $45 \%$ of the patients, compared to only $25 \%$ of transplanted patients without GVHD. The glandular density was almost 2 times lower in the submucosa of HSCT with GVHD. The mucosal eosinophil count was three times higher in patients with GVHD. Moderate to severe edema occurred in 54\% of patients with GVHD and in only $12 \%$ of those without GVHD. Moreover, $27 \%$ of the transplanted patients with severe GVHD had fibrosis, compared to no one from the transplanted without GVHD group. Figure 1 shows the histological sections of optical microscopy, comparing HSCT patients with and without GVHD.

Regarding the parameters studied in transmission electron microscopy, there was a significant difference in the presence of microvilli (Table 3). All the HSCT patients without GVHD had microvilli on the tops of ciliated cells, compared to half of those with GVHD. The primary modification of the ultrastructure is the compound cilia in both groups. Squamous metaplasia occurs in approximately $20 \%$ of patients in both groups. Despite the amount of cilia not differing significantly, half of the patients with GVHD have no cilia on the surfaces of the ciliated cells, whereas the cilia are absent in only $37 \%$ of HSCT patients without GVHD. Approximately $72 \%$ of transplanted patients with GVHD have rare or no goblet cells in the nasal respiratory epithelium. Figure 2 shows the histological sections under electron microscopy among the different groups.

When the rhinosinusitis recurrence and epithelium aspects were compared under optical and transmission electron microscopy, there were no significant differences among the recipients with and without GVHD, except for a tendency towards an absence of cilia among those with the highest recurrence of rhinosinusitis (Tables 4 and 5). However, only $15 \%$ of patients with less frequent rhinosinusitis recurrences have squamous metaplasic epithelium, compared with $33 \%$ of those with more than 3 episodes of rhinosinusitis. The nasal epithelia of those with increased recurrence of rhinosinusitis had half as many microvilli.

Surprisingly, the occurrence of rhinosinusitis showed no significant relation to myeloablation or chronic GVHD. However, $80 \%$ of transplanted patients who underwent a myeloablation had a higher rhinosinusitis recurrence, compared to only $20 \%$ of non-myeloablative HSCT patients. Similarly, $70 \%$ of patients with chronic GVHD had more than 3 cases of rhinosinusitis, compared to only 30\% without GVHD.

However, the comparison between recipients who had no rhinosinusitis and those who had more than three recurrences shows a significant ciliary decrease as the occurrence of rhinosinusitis increases $(\mathrm{P}=0.008)$. Although not significant, a $67 \%$ decrease or absence of goblet cells may occur in transplanted patients with higher recurrences of rhinosinusitis, compared to a $16 \%$ decrease in this cell among patients without rhinosinusitis. The data comparing the occurrence of rhinosinusitis and its ultrastructural aspects are presented in Table 6.

\section{Discussion}

It is known that there is a higher prevalence of bacterial rhinosinusitis and that its recurrence in hematopoietic stem cell-transplanted patients is still 4.3 times more likely in those with chronic GVHD [6,16-18]. Given our previous results, it was found that patients undergoing HSCT had significant epithelial damage after the transplants, which may increase the risk of respiratory infection via the mechanical disruption of the barrier protection [11]. Moreover, opportunistic pathogens due to immunosuppression may cause increased harm to the epithelium that maintains the sinus infection [2-4].

As our current results show, the ultrastructure of the nasal mucosa of allogeneic transplanted patients with GVHD in the presence of rhinosinusitis indeed appears to have fewer microvilli, cilia (50\%) and goblet cells (72\%). These findings are consistent with the findings of our previous study, which showed a significant decrease in cilia (77\%) and goblet cells (50\%) in the sinonasal mucosa of HSCT compared to immunocompetent $(0 \%)$ patients, independent of the occurrence of rhinosinusitis [11]. This epithelial damage and globetet cell decrease may cause a mucosal dryness that harms the proper mucociliary clearance while maintaining adequate lubrication to keep the defense proteins (lactoferrins, lysosomes) and immunoglobulins within the mucosal surface, further decreasing the respiratory defense [19].

Because sinus infections are more prevalent in hematopoietic stem cell transplants (HSCT) with GVHD, we expected to find different epithelial changes in both groups of transplanted patients; however, we did not find any significant histological differences, despite a denser apparent inflammatory lymphocytic and eosinophilic infiltration, fewer submucosal glands and more edema and subepithelial fibrosis. We did not observe a higher percentage of apoptotic bodies in HSCT patients with GVHD and rhinosinusitis, in contrast to the results of a previous study that showed a significant increase in the intraepithelially transplanted apoptotic bodies compared to those in immunocompetent patients (6x greater). Among patients with HSCT and with GVHD, this rate was 3 times that of those with transplants and without GVHD $[11,20]$.

Contrary to expectations, the histological abnormalities found in the nasal mucosa of allogeneic recipients with and without GVHD in the occurrence of rhinosinusitis are similar to those of immunocompetent patients with chronic or recurrent rhinosinusitis, such as leukocyte infiltration, squamous metaplasia, glandular hyperplasia, increased goblet cells and the presence of microvilli [2125]. Although HSCT patients have a denser inflammatory infiltrate compared to immunocompetent patients, as in a previous study, this present study suggests that rhinosinusitis does not seem to trigger specific tissue damage in the respiratory epithelium, especially in those with GVHD. Thus, a higher prevalence of rhinosinusitis in allogeneic recipients with GVHD does not seem to occur because of primary epithelial abnormalities but instead due to the immunosuppression triggered by GVHD and its treatment.

There were no significant epithelial abnormalities found, except for the microvilli increases in allogeneic recipients without GVHD and with rhinosinusitis. A recent study showed that pro-inflammatory cytokines released in the respiratory epithelium due to chronic rhinosinusitis

\begin{tabular}{|l|c|c|c|}
\hline Light microscopy & Without GVHD & With GVHD & P \\
\hline Moderate Inflammatory infiltrate & $2(25 \%)$ & $5(45 \%)$ & 0.669 \\
\hline Intraepithelial lymphocytes (no./hpf) & 12 & 7.2 & 0.098 \\
\hline Apoptotic body (no./hpf) & 5.3 & 6.6 & 0.482 \\
\hline Eosinophils (no./hpf) & 4.2 & 14.4 & 0.641 \\
\hline Glandular density (no./hpf) & 11 & 6.7 & 0.126 \\
\hline Moderate/severe edema & $1(12 \%)$ & $6(54 \%)$ & 0.16 \\
\hline Fibrosis & 0 & $3(27 \%)$ & 0.332 \\
\hline Basal membrane (mm) & 0.048 & 0.032 & 0.858 \\
\hline
\end{tabular}

Table 2: Analysis of the sinonasal optical microscopy of patients transplanted with hematopoietic stem cells, with and without graft versus host disease (GVHD) epithelium. Fisher's exact test and Wilcoxon analysis with $P$ value $<0.005$. (No $\mathrm{hpf}=$ number per field of greatest increase, $\mathrm{mm}=$ millimeters). 
Citation: Ortiz É, Meirelles LR, Vigorito AC, Sakano E, Nicola EMD (2014) Sinonasal Ultrastructure of the Hematopoietic Stem Cell Transplant and Chronic Graft-versus-host Disease with Rhinosinusitis. J Stem Cell Res Ther 4: 157. doi:10.4172/2157-7633.1000157

Page 4 of 7
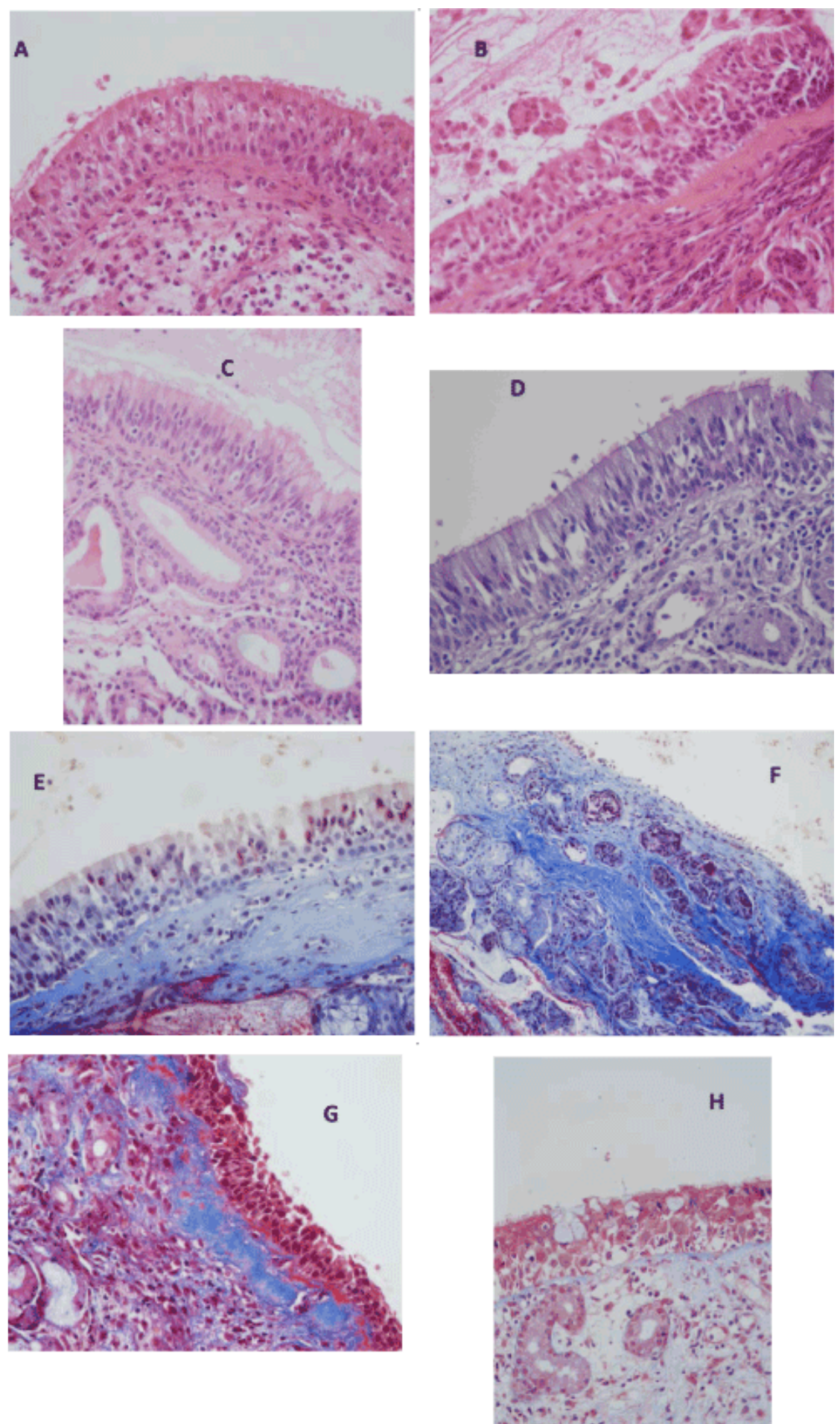

Figure 1: Histological sections of the nasal epithelium of transplanted patients under optical microscopy. (A and B) intense and moderate eosinophilic inflammatory infiltrate and submucosal epithelial (HE). (C and D) Lymphocytic inflammatory infiltrate epithelial (PAS). (E) Ciliated epithelium, pseudostratified without fibrosis (Massom). (F) subepithelial (Massom) fibrosis. (G) Thickening of the basement membrane (arrow) in Massom. (H) Submucosal edema (Massom).

can inhibit ciliogenesis, decreasing the formation of centrioles and basal bodies and thus halting the elongation of these centrioles to form microvilli and short or deformed cilia [26]. This would preclude the proper function of ciliary beating and mucociliary clearance. Other studies have shown that some infections can cause transient changes in the ciliary ultrastructure. Influenza, adenovirus, parainfluenza virus, respiratory syncytial virus and herpes can cause ciliary abnormalities that improve in approximately 10 weeks [1]. In chronic and recurrent sinusitis, Staphylococcus aureus, Haemophilus influenzae and Pseudomonas aeruginosa cause more persistent abnormalities in the 
Citation: Ortiz É, Meirelles LR, Vigorito AC, Sakano E, Nicola EMD (2014) Sinonasal Ultrastructure of the Hematopoietic Stem Cell Transplant and Chronic Graft-versus-host Disease with Rhinosinusitis. J Stem Cell Res Ther 4: 157. doi:10.4172/2157-7633.1000157

Page 5 of 7

\begin{tabular}{|l|c|c|c|}
\hline Electron microscopy & Without GVHD & With GVHD & P \\
\hline Cilia (absence) & $3(37 \%)$ & $7(50 \%)$ & 0.747 \\
\hline Ultrastructure (compound cilia) & $3(37.5 \%)$ & $2(14.2 \%)$ & 0.412 \\
\hline Normal Ciliary Orientation & $4(50 \%)$ & $4(31 \%)$ & 0.482 \\
\hline Squamous metaplasia & $2(25 \%)$ & $3(21 \%)$ & 1 \\
\hline Microvilli & $8(100 \%)$ & $8(57 \%)$ & 0.05 \\
\hline Goblet cells (decreased labsence) & $3(37 \%)$ & $10(72 \%)$ & 0.271 \\
\hline $\begin{array}{l}\text { Cytoplasmatic mitochondria } \\
\text { (decreased labsence) }\end{array}$ & $4(50 \%)$ & $8(57 \%)$ & 0.685 \\
\hline Cytoplasmatic vacuolization & $4(50 \%)$ & $6(43 \%)$ & 1 \\
\hline
\end{tabular}

Table 3: Analysis of the nasal epithelium of hematopoietic stem cell transplanted patients with and without the Graft Versus Host Disease (GVHD) by transmission electron microscopy. Fisher's exact test and Wilcoxon analysis with $\mathrm{P}=\mathrm{P}$ value (significance<0.05).
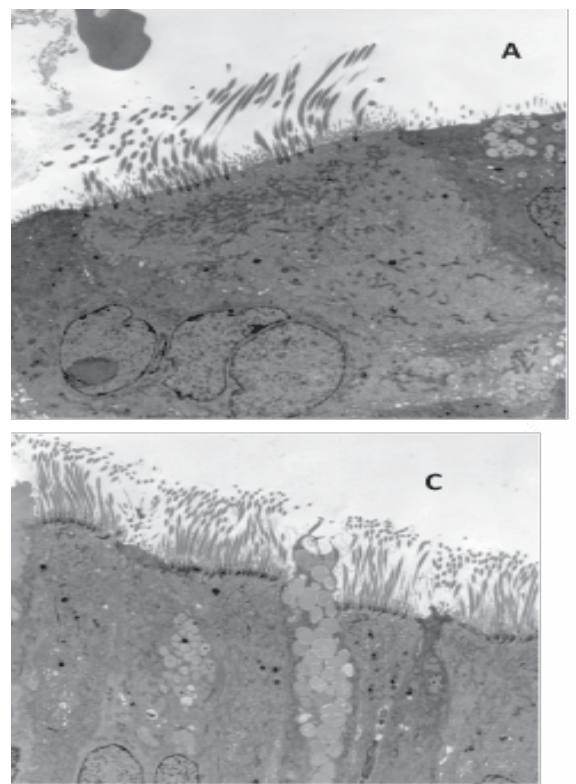

sinonasal mucosa. This is possibly due to the release of toxins and proteases by these bacteria, in addition to the release of elastase by the intraepithelial macrophages that decrease the ciliary beating and disorganize the cilia [26,27].

Unlike $50 \%$ of the abnormalities in the ciliary ultrastructure found in HSCT in a previous study [11], the current study found that approximately $20 \%$ of the compound cilia in both groups transplanted with rhinosinusitis mucosa did not differ from that in immunocompetent patients with chronic rhinosinusitis (17-45\%). Compound cilia consist of multiple axonemes surrounded by a single membrane and can be found in patients with chronic diseases of the nasal mucosa, such as rhinitis, sinusitis and allergy. Compound cilia results from the prompt regeneration of the mucosal barrier after
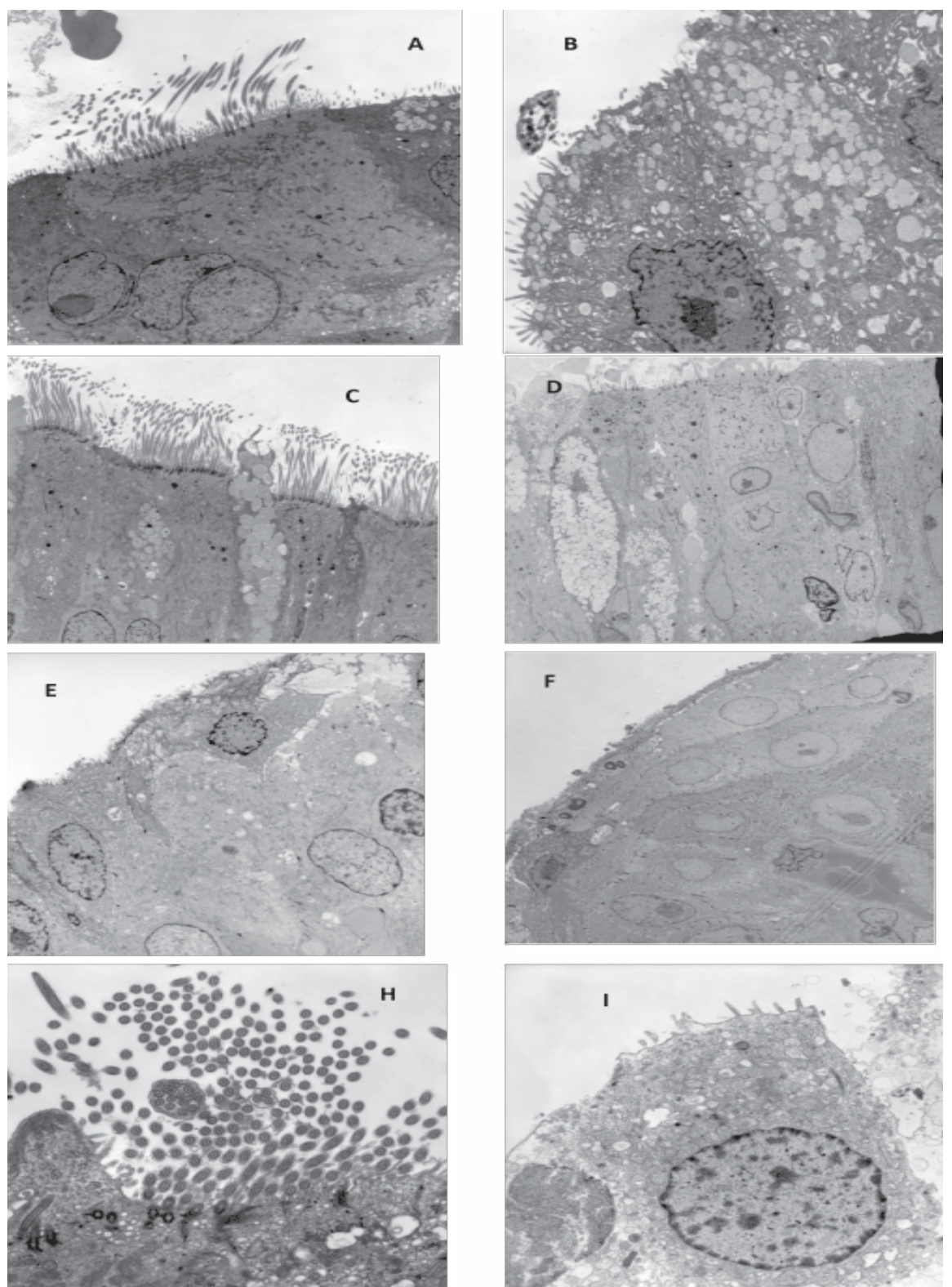

Figure 2: Ciliated nasal epithelium of transplanted patients without GVHD (right column) and with GVHD (left column) under transmission electron microscopy. (A) Ciliated cells with cilia decrease and microvilli increase. (B) Pseudostratified ciliated epithelium without cilia. (C) Normal ciliated epithelium with goblet cells. (D) Ciliated epithelium without cilia and mononuclear cells migrating to the surface (arrow). (E) Epithelium into a process of squamous metaplasia without cilia. (F) Squamous metaplasia. (G) Compound cilia. (H) Ciliated cells without cilia and mitochondria and with cytoplasmic vacuolization. 
Citation: Ortiz É, Meirelles LR, Vigorito AC, Sakano E, Nicola EMD (2014) Sinonasal Ultrastructure of the Hematopoietic Stem Cell Transplant and Chronic Graft-versus-host Disease with Rhinosinusitis. J Stem Cell Res Ther 4: 157. doi:10.4172/2157-7633.1000157

Page 6 of 7

\begin{tabular}{|l|c|c|c|}
\hline Light microscopy & 1 or 2 RS & >3 RS & P \\
\hline Moderate inflammatory infiltrate & $4(36 \%)$ & $3(38 \%)$ & 0.343 \\
\hline Intraepithelial Lymphocytes (hpf) & 6 & 12 & 0.62 \\
\hline Apoptotic body (hpf) & 5.3 & 6.6 & 0.301 \\
\hline Eosinophils (hpf) & 14.4 & 3.6 & 0.219 \\
\hline Glandular density (hpf) & 6.8 & 11 & 0.62 \\
\hline Moderate/severe edema & $4(36 \%)$ & $3(38 \%)$ & 0.567 \\
\hline Moderate/severe fibrosis & $4(36 \%)$ & $5(63 \%)$ & 0.74 \\
\hline Basal Membrane (mm) & 0.048 & 0.032 & 0.593 \\
\hline
\end{tabular}

Table 4: Rhinosinusitis recurrence and the nasal epithelium aspects under optical microscopy in patients with and without chronic graft-versus-host disease (GVHD). ( 1 or $2 \mathrm{RS}=1-2$ episodes of rhinosinusitis $>3 \mathrm{RS}=$ more than 3 episodes of rhinosinusitis; $\mathrm{P}=\mathrm{P}$ value; No./hpf: number per $40 \mathrm{x}$ high-power field, RS rhinosinusitis).

\begin{tabular}{|l|c|c|c|}
\hline Electron microscopy & 1 or 2 RS & $\mathbf{> 3 ~ R S ~}$ & P \\
\hline Cilia (absence) & $\mathbf{3 ( 2 3 \% )}$ & $\mathbf{7 ( 7 7 \% )}$ & $\mathbf{0 . 0 8}$ \\
\hline Ultrastructure (compound cilia) & $4(31 \%)$ & $1(11 \%)$ & 0.163 \\
\hline Normal ciliary orientation & $6(46 \%)$ & $2(22 \%)$ & 0.367 \\
\hline Squamous metaplasia & $2(15 \%)$ & $3(33 \%)$ & 0.609 \\
\hline Microvilli & $11(85 \%)$ & $5(56 \%)$ & 0.178 \\
\hline Goblet cells (decreased labsence) & $7(54 \%)$ & $6(67 \%)$ & 0.764 \\
\hline $\begin{array}{l}\text { Cytoplasmatic mitochondria } \\
\text { (decreased labsence) }\end{array}$ & $4(31 \%)$ & $7(78 \%)$ & 0.164 \\
\hline Cytoplasmatic Vacuolization & $5(38 \%)$ & $5(56 \%)$ & 0.666 \\
\hline
\end{tabular}

Table 5: Rhinosinusitis recurrence and the nasal epithelium aspects under transmission electron microscopy in patients with and without chronic graft-versushost disease (GVHD). (1 or 2 RS=1-2 episodes of rhinosinusitis; >3 RS=more than 3 episodes of rhinosinusitis, $P=P$ value $)$.

\begin{tabular}{|l|c|l|c|c|}
\hline Transmission electron microscopy & Without RS & 1 or 2 RS & >3 RS & P \\
\hline Cilia (absence) & $\mathbf{0}$ & $\mathbf{3}$ & $\mathbf{7}$ & $\mathbf{0 . 0 0 8}$ \\
\hline Ultrastructure (compound cilia) & 2 & 3 & 1 & 0.178 \\
\hline Normal ciliary orientation & 5 & 6 & 2 & 0.06 \\
\hline Squamous metaplasia & 0 & 2 & 3 & 0.388 \\
\hline Microvilli & 5 & 11 & 5 & 0.343 \\
\hline Goblet cells (decreased / absence) & 1 & 7 & 6 & 0.598 \\
\hline $\begin{array}{l}\text { Cytoplasmatic mitochondria } \\
\text { (decreased / absence) }\end{array}$ & 1 & 5 & 7 & 0.159 \\
\hline Cytoplasmatic vacuolization & 3 & 5 & 5 & 0.885 \\
\hline
\end{tabular}

Table 6: Analysis of the ultrastructure of the nasal mucosa in relation to the occurrence of rhinosinusitis under transmission electron microscopy. (RS: rhinosinusitis; $P=P$ value).

inflammatory damage, but it can also occur in mucosal regeneration post-sinus surgery in mice with decreased mucociliary clearance. However, the compound cilia found in the solitary cilia cell cannot be translated into changes in the mucociliary clearance. The effects of compound cilia on the nasal mucosa and its clearance are still unclear. As in rhinitis and rhinosinusitis, it is unclear whether the cilia are the cause or the consequence of the sinonasal disease [22,23,28-30].

Although there are sinonasal epithelial histological abnormalities in transplanted patients, there is a greater tendency to decrease the cilia in the respiratory epithelium in recurrent rhinosinusitis. It seems that the more frequent the rhinosinusitis, the more squamous metaplasia, fewer cilia on the surfaces of ciliated cells and fewer microvilli. Therefore, the recurrence of rhinosinusitis may be an aggravating factor for rhinosinusitis in HSCT patients. However, other factors triggering the higher prevalence and recurrence of nasosinusal infections in this group of patients should be considered, such as immunosuppression, tissue damage caused by the transplant process (total body irradiation, chemotherapy) and/or possible sinonasal anatomical changes [31].
Although not statistically significant, the myeloablative HSCT seems to contribute to a higher recurrence of rhinosinusitis, as $80 \%$ of transplant patients undergoing myeloablation have a higher recurrence of rhinosinusitis, compared to $20 \%$ of non-myeloablative. Similarly, although not significant, GVHD also contributed to the recurrence of rhinosinusitis, with $70 \%$ of patients with GVHD having more than 3 cases of rhinosinusitis, compared to only $30 \%$ of those without GVHD. These data and the insignificant findings of the histological changes of the nasal mucosa suggest that immunosuppression remains the most important causal factor for the recurrence of rhinosinusitis.

\section{Conclusion}

Patients who received hematopoietic stem cell transplants do not differ in their sinonasal histological abnormalities in the presence of rhinosinusitis, except for an increased number of microvilli in those without chronic GVHD.

The recipients with and without chronic GVHD only had a decrease of the cilia in the nasal epithelium according to their increased rhinosinusitis recurrence.

\section{References}

1. López-Medrano F, Aguado JM, Lizasoain M, Folgueira D, Juan RS, et al. (2007) Clinical Implications of Respiratory Virus Infections in Solid Organ Transplant Recipients: A Prospective Study. Transplantation 84: 851-856.

2. Savage DG, Taylor P, Blackwell J, Chen F, Szydlo RM, et al. (1997) Paranasa sinusitis following allogenic bone marrow transplant. Bone Marrow Transplant 19: $55-59$.

3. Mortellaro C, Barat V, Nesi F, Bello L, Bologna G, et al. (2012) Intercurrent Infectious Diseases in Post-stem Cell Transplant Patients: Paranasal Sinusitis. J Craniofac Surg 23: 153-157.

4. Belinger N (1985) Sinusitis in imunodeficient and imunossupressed patients. Laryngoscope 95: 29-33.

5. Mirza N, Lanza DC (2000) Diagnosis and Management of Rhinosinusitis before Schedule Immunosupression. Otolaryngol. Otolaryngol Clin North Am 33: 313-321.

6. Thompson AM, Couch M, Zahurak ML, Johnson C, Vogelsang GB (2002) Risk Factors for post-stem cell transplant sinusitis. Bone Marrow Transplant 29: 257-261.

7. Rizzieri DA, Koh LP, Long GD, Gasparetto C, Sullivan KM, et al. (2007) Partially matched, nonmyeloablative allogeneic transplantation: Clinical outcomes and immune reconstitution. J Clin Oncol 25: 690-697.

8. Ricardo Pasquini, Fundamentals of Biology and Transplantation of Hematopoietic Cells - Fundamentals in Hematology, chapter 81: 913-934.

9. Shulman HM, Kleiner D, Lee SJ, Morton T, Pavletic SZ, et al. (2006) Histopathologic diagnosis of chronic graft-versus-host disease: National Institutes of Health Consensus Development Project on Criteria for Clinical Trials in Chronic Graft-versus-Host Disease: II. Pathology Working Group Report. Biol Blood Marrow Transplant 12: 31-47.

10. Rieger K, Loddenkemper C, Maul J, Fietz T, Wolff D, et al. (2006) Mucosa FOXP3+ regulatory cells are numerically deficient in acute and chronic GVHD. Blood 107: 1717-1723.

11. Ortiz E, Sakano E, Meirelles LR, Vigorito AC, Cintra ML, et al. (2011) Histologica features of the nasal mucosa in hematopoietic stem cell transplantation. Am J Rhinol Allergy 25: 191-195.

12. Cordonnier C, Gilain L, Ricolfi F, Deforges L, Girard-Pipau F, et al. (1996) Acquired ciliary abnormalities of nasal mucosa in marrow recipients. Bone Marrow Transplant 17: 611-616.

13. (2008) Diretrizes Brasileiras de Rinossinusite. Suppl Brazilian J Otolaryngology 74

14. Fokkens WJ, Lund VJ, Mullol J, Bachert C, Alobid I, et al. (2012) European Position Paper on Rhinosinusitis and nasal polyps. Rhinol Suppl 50: 1-12.

15. Wake M, Takeno S, Hawke M (1994) The uncinate process: a histological and morphological study. Laryngoscope 104: 364-369.

16. Ortiz E, Sakano E, De Souza CA, Vigorito A, Eid KA (2006) Chronic GVHD 
Citation: Ortiz É, Meirelles LR, Vigorito AC, Sakano E, Nicola EMD (2014) Sinonasal Ultrastructure of the Hematopoietic Stem Cell Transplant and Chronic Graft-versus-host Disease with Rhinosinusitis. J Stem Cell Res Ther 4: 157. doi:10.4172/2157-7633.1000157

predictive feature factor for rhinosinusitis in Bone Marrow Transplant. Braz $J$ Otorhinolaryngology 72: 328-332.on YW, Yi SY, Jang JH, Kim K, Kim SJ, et al. (2011) Retrospective analysis of paranasal sinusitis in patients receiving hematopoietic stem cell transplantation. Int J Hematol 93: 383-388.

17. Junghanss C, Marr KA, Carter RA, Sandmaier BM, Maris MB, et al. (2002) Incidence and outcome of bacterial and fungal infections following nonmyeloablative compared with myeloablative allogeneic hematopoietic stem cell transplantation: a matched control study. Biol Blood Marrow Transplant 8: $512-520$.

18. Abdelmalik SW (1997) Microscopic Study of Certain Age-Related Structural Changes of Maxillary Sinus Lining Epithelium in Albino Rats. Microsc Res Tech 254: 39-42.

19. Socié G, Mary JY, Lemann M, Daneshpouy M, Guardiola P, et al. (2004) Prognostic value of apoptotic cells and infiltrating neutrophils in graft-versushost disease of the gastrointestinal tract in humans: TNF and Fas expression. Blood 103: 50-57.

20. Shlomchik WD, Lee SJ, Couriel D, Pavletic SZ (2007) Transplantation's greatest challenges: Advances in chronic graft-versus-host disease. Biol Blood Marrow Transplant 13: 2-10.

21. Toskala E, Rautiainen M (2003) Eletron Microscopy assessment of the recovery of sinus mucosa after sinus surgery. Acta Otolaryngol 123: 954-959.

22. Dorgam, JV, Melo, VR, Anselmo-Lima WT (2004) Estudo histológico e ultraestrutural da mucosa do seio maxilar em pacientes com rinossinusite crônica e polipose nasossinusal. Braz J Otolaringol 70: 7-13.
23. Namba N, Shinagawa K, Fujii N, Maeda Y, Ishimaru F, et al. (2007) Predominant infiltration of monocytes in chronic graft-versus-host disease. Transplantation 83: $220-224$

24. Jacopo Gain, Lea Calo, Fausta Ardito, Micaela Imperiali, Ezio Bassotti, et al. (2008) Damage to Ciliated Epithelium in Chronic Rhinosinusitis: What Is the Role of Bacterial Biofilms? Ann Otol Rhinol Laryngol 117: 902-908.

25. Lai Y, Chen B, Shi J, Palmer JN, Kennedy DW, et al. (2011) Inflammationmediated upregulation of centrosomal protein 110, a negative modulator of ciliogenesis, in patients with chronic rhinosinusitis. J Allergy Clin Immunol 128 1207-1215.

26. Joki S, Toskala E, Saano V, Nuutinen J (1998) Correlation between ciliary beat frequency and the structure of ciliated epithelia in pathologic human nasa mucosa. Laryngoscope 108: 426-430.

27. McAuley JR, Anand VK (1998) Clinical significance of compound cilia Otolaringology Head Neck Surg 118: 685-687.

28. Paschoal IA, Altemani AMA, Arteta LMC, PAlombini BC, Alves MRA, et al (1992) Ultraestrutura ciliar à microscopia eletrônica de transmissão. Jornal de Pneumologia 18: 1145-1160.

29. Cowan MJ, Gladwin MT, Shelhamer JH (2001) Disorders of Ciliary Motility. Am J Med Sci 321: 3-10.

30. Kern RC, Conley DB, Walsh W, Chandra R, Kato A, et al. (2008) Perspectives on the etiology of chronic rhinosinusitis: An immune barrier hypothesis. Am J Rhinol 22: 549-559. 